\title{
A PAISAGEM, A NATUREZA E A NATUREZA DAS ATITUDES DO HOMEM
}

\section{MARLA ANGELA FAGGIN PEREIRA LEITE}

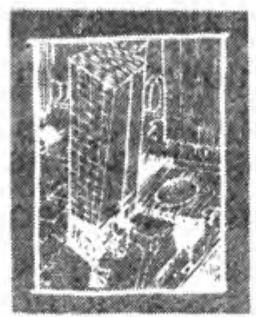

A paisagem, como manifestação da criatividade humana, apresenta uma essência dupla: é um fato físico, objetivo, categorizável e é um processo criativo contínuo, incapaz de encontrar um arranjo definitivo, de configurar-se como uma realidade imóvel, de apresentar uma concepção estática. Aomesmo tempo que é uma construção espacial coletiva, rica em detalhes minuciosos, é também capaz de oferecer grandes visões de conjunto, e talvez seja seu caráter não finito, associado a essa complexidade qualitativa e dimensional o que torna difícil sua apreensão global, sua leitura profunda.

Embora a paisagem encerre uma infinidade de fatores e elementos e seja, portanto, objeto de interesse e estudo de diversos campos de conhecimento, as idéias envolvidas na sua concepção e na sua "construção", estão relacionadas, de um lado, com seu conhecimento e interpretação e, de outro, com a experiência individual ou coletiva com respeito a ela ${ }^{1}$

Se é possível, através do conhecimento e interpretação da paisagem, elencar e até mesmo precisar seus elementos fundamentais, deve-se reconhecer que esses elementos não são duradouros, mas ao contrário, estão em contínua e incessante mutação. Da mesma forma, a experiência individual ou coletiva está, também ela, sujeita a variações contínuas, a uma dinâmica que deriva do processo histórico de qualificação, sobre o qual incidem os fatores mais variados, caracterizados pela evolução das relações políticas, econômicas, sociais, pelo desenvolvimento das técnicas, das artes, das religiões da filosofia.

O homem sempre criou ao seu redor um ambiente que é uma projeção de suas idéias abstratas. Cada momento histórico tem uma paisagem, reflexo da relação circunstancial entre o homem e a natureza e que pode ser vista como a ordenação do ambiente, de acordo com uma imagem ideal.

As mudanças nas atitudes do homem com relação à paisagem sempre foram marcadas por uma poderosa atração pela natureza. Essa atração está presente, tanto na paisagem submissa dos jardins do mundo clássico ${ }^{2}$, quanto no caráter social da paisagem contemporânea ${ }^{3}$ 
A forma pela qual a paisagem é projetada e construída, reflete, de perto, certos gostos e modas que se baseiam, tanto na observação objetiva do ambiente, quanto em conceitos filosóficos permanentemente em evolução.

Desde que se admita que a paisagem é uma mistura de arte (caracterizada pela escolha) e ciência (caracterizada por fatos objetivos), é possível compreender que suas modificações, a renovação das formas antigas ou a criação de novas formas que atendam a novos estilos de vida, são dependentes das conquistas em cada um desses campos, dependentes do valor que é atribuído a eles em cada momento.

Em resumo, mais importante que as mudanças da noção de paisagem são as mudanças da nossa capacidade de captar-lhe a essência, de compreender algo que preexiste a nossa compreensão 4

Até o séc. XVII a distinção entre as artes e as ciências, se era reconhecida, era muito mal definida. É aceito de maneira geral, que a fundação da Royal Society, em 1660, constituiu um marco do reconhecimento formal da ciência como algo diferente das $\operatorname{artes}^{5}$ Infelizmente, essa distinção é a raiz dos muitos problemas existentes para o entendimento da atração que a paisagem exerce sobre as pessoas, de muitas formas diferentes. Para que o contato com a paisagem se dê simultaneamente através de seu conhecimento e interpretação e da experiência individual e coletiva a seu respeito, é necessária uma aproximação maior entre seu lado artístico e seu lado científico. A paisagem, ao contrário de outras formas de arte, é efêmera. Seus princípios de organização, assim como os da arquitetura, da pintura, da música e da literatura, são constantemente questionados e modificados pela evolução da sociedade, das ciências e das técnicas. Entretanto, essas outras formas de arte possuem um tipo de registro que permanece através dos tempos, o que não acontece com a paisagem que, ao assumir novas feições, anula as anteriores ou conserva delas apenas alguns vestígios.

\section{PAISAGEM DOS OBJETOS}

As civilizações do mundo antigo, estabeleceram com o ambiente uma relação de sobrevivência imediata. Suas preocupações em controlar e embelezar a paisagem, envolviam, num conjunto solidário, conhecimentos de botânica, agricultura, engenharia e estética, com a religião desempenhando um papel maior ou menor na explicação do inexplicável, de acordo com a convivência mais ou menos harmoniosa dos homens com a natureza. Não havia uma visão de conjunto, uma vez que as relações com o entorno eram estabelecidas apenas numa área mais ou menos bem delimitada, onde se desenvolvia a vida 
das pessoas. A escolha e a disposição dos elementos construídos obedeciam a princípios filosóficos, religiosos e morais. A contemplação da natureza, freqüentemente, era uma forma de fugir da monotonia de uma paisagem fragmentada, composta por uma coleção de objetos dispostos de forma a melhor atender às necessidades básicas da população.

Os jardins suméricos eram, na verdade, uma praça fechada contra o mundo hostil, implantados geometricamente, sendo seu conteúdo básico formado por árvores e canais de irrigação. Esses jardins, objeto de veneração, eram a expressão concreta da filosofia da inevitabilidade que decorria das precárias condições de uma vida, cuja finalidade era a contemplação de um futuro eterno e sereno, simbolizado pelo céu ${ }^{6}$

A primeira expansão formal da área habitacional, em direção ao ambiente circundante, surgiu com os parques de caça assírios, decorrência da domesticação dos cavalos. Essa idéia de expansão continuou marcando a paisagem persa: Persépolis foi construída sobre um imenso patamar que se projetava para dominar visualmente o vale abaixo.

Os assentamentos muçulmanos incorporaram à expansão para o ambiente, uma maior integração entre o interior e o exterior (a casa e o jardim). Esse procedimento com relação à continuidade dos espaços livres e edificados, influenciou grandemente a paisagem da Espanha após as invasões muçulmanas.

$\mathrm{Na}$ Índia mongólica, a paixão intuitiva pela natureza, que os imperadores mongóis herdaram de seus ancestrais, foi igualada pelas preocupações de integrar os edifícios com o entorno, herança muçulmana: enquanto a geometria dos jardins permanecia tradicionalmente monótona, havia a concepção inovadora de uma paisagem exterior grandiosa e selvagem ${ }^{7}$

$\mathrm{Na}$ Índia antiga, a fertilidade da natureza dava ao povo inclinação, tempo e condições espirituais para a contemplação metafísica. A maior preocupação era tornar visível o mundo invisível, onde a espiritualidade humana desempenhava um papel importantíssimo no significado da vida.

Na China, ao contrário, o código moral de Confúcio, tinha um caráter mais comportamental do que religioso. A ênfase no culto da solidão, no individual e não na comunidade, na harmonia interna instintiva e não na aparência exterior regrada, levou a uma sensibilidade especial com relação à paisagem: seus elementos básicos eram as pedras, as montanhas e as águas silenciosas; as fronteiras entre os espaços foram eliminadas ou ao menos subdimensionadas; a imaginação, tal como o espírito, devia correr livre em espaços amplos e abrangentes. 
Também no Japão, onde a imensidão do céu e do oceano dominavam e até mesmo oprimiam as ilhas, a relação com a paisagem desenvolveu-se mais através dos elementos do universo como um todo do que através dos elementos da vida cotidiana.

Nas civilizações pré-colombianas do México e da América Central, a base da organização social se apoiava na adoração ao Sol. Os maias e os astecas construíram enormes centros cerimoniais que dominavam a paisagem, concebida como um microcosmo, ordenado e geometrizado, das montanhas e vales circundantes. Em contraste com essas civilizações teocráticas, os incas, no Peru, estavam permanentemente preocupados com a sobrevivência e, por isso, sua paisagem tinha um terraço de agricultura e as fortificações, ao invés de para a construção de templos ou monumentos religiosos.

No Egito, a filosofia de vida e morte que imperava tinha como base um ambiente único em sua constância e dependência. Pela previsibilidade dos eventos naturais, pela segurança econômica e pela relativa proteção contra invasões, foi possível projetar o futuro como uma extensão eterna do presente. A paisagem do Egito dos faraós refletia, de forma clara, a filosofia de que a vida na terra era apenas uma introdução a uma vida eterna, similar.

A autocontenção econômica de Esparta, dentro de suas montanhas, criou uma forma de pensamento extremada, defensiva, estéril e pouco liberal. A paisagem resultante desse modo de vida, expressa bem os progressos do homem para controlar seu ambiente e seu destino.

Em Atenas, onde o ambiente era simultaneamente perigoso e imprevisível, a situação era oposta. Contrariando a idéia da auto-suficiência material e arriscando tudo na navegação, a sociedade ateniense desafiou o modo de vida da época: em seu lugar emergiu a filosofia da razão e da unidade de todas as coisas. A essência da construção da paisagem era de que toda arquitetura, fosse templo, teatro, praça ou habitação, deveria harmonizar-se com o ambiente.

Os gregos foram, provavelmente, o primeiro povo urbano e seus hábitos sociais estavam centrados nas conversas informais, palestras, competições esportivas, etc. $\mathrm{Na}$ organização de sua paisagem estão as prováveis origens do parque moderno 8

Na sociedade romana os bens coletivos eram os que se referiam à agricultura e à fertilidade das terras. Os romanos eram homens do campo e, portanto, a contemplação do crescimento das árvores, do constraste entre as folhagens, o desfrutar da sensação de paz dos campos e florestas eram fins em si mesmos. 
As leis eram a base da administração civil e militar e o senso de obediência e respeito surgiu da rigorosa disciplina que era imposta aos cidadãos. Entretanto, em contraste com os poetas gregos, para os quais a paisagem era algo épico a ser conquistado ${ }^{9}$, os poetas romanos tinham uma original e criativa apreciação da beleza da paisagem ${ }^{10}$

As civilizações da Antigüidade estiveram tão profundamente impregnadas pelo sentido de adaptação e sobrevivência humana, que sua paisagem, na maior parte das vezes, ficou reduzida a uma conseqüência da disposição de elementos que satisfizessem às necessidades essenciais do corpo ou do espírito. Seu conjunto era sempre fragmentado, freqüentemente fechado para o mundo exterior, com o aspecto técnico dominando ou até mesmo anulando o aspecto estético.

\section{OS SÍMBOLOS, OS FATOS, O FANTÁSTICO}

A partir da Idade Média, o aparecimento e o desenvolvimento da pintura da paisagem, registrando as diversas fases da concepção da natureza, foi o primeiro marco de um ciclo no qual o espírito humano começa a se alimentar da harmonia daquilo que o cerca.

A paisagem, nessa época, era de um desenho mais intuitivo do que consciente e de um apelo que se apoiava largamente na mensagem do simbolismo. Os símbolos com os quais a arte medieval representava os objetos naturais não tinham muita relação com sua real aparência. De certo modo, esses símbolos eram a base do êxito da filosofia medieval: ọs iletrados, que, numericamente, ultrapassavam em muito os letrados, eram ensinados por uma religião internacional e brilhantemente organizada, que a vida terrena não era mais que um breve interlúdio e, portanto, o ambiente em que era vivida, não devia absorver excessivamente a atenção ${ }^{11}$ Os homens estavam tão preocupados com a sobrevivência do corpo neste mundo e da alma no próximo, que não podiam sofisticar muito a paisagem cotidiana.

Os campos significavam apenas trabalho duro; a costa marítima significava perigo de tempestades e pirataria. E, para além dessas partes mais ou menos aproveitáveis da superfície da terra, estendia-se uma área interminável de florestas e pântanos.

A natureza, no seu conjunto, era perturbante, vasta e atemorizante e as vastidões abriam no espírito muitos pensamentos perigosos. Porém, paralelamente a essa desconfiança em relação à natureza, desenvolveu-se uma faculdade de simbolizar características da mentalidade medieval: as baladas dos 
trovadores e os escritos da época descrevem a paisagem das florestas como uma imagem idilica do mundo ${ }^{12}$.

Entretanto, o sentido de isolamento da comunidade dentro de um mundo hostil, levou a sociedade a um estado de espírito segundo o qual todos os objetos materiais eram encarados como símbolos de verdades espirituais ou episódios das Sagradas Escrituras ${ }^{13}$

Os elementos naturais, numa primeira etapa, foram observados individualmente e simbolizavam qualidades divinas. Numa segunda etapa, sua observação passou a dar-se a partir de um conjunto que pudesse ser abrangido pela imaginação e que, no seu todo, representasse a perfeição: surge o jardim medieval, que tinha como característica comum o espaço fechado, íntimo, emparedado, fortemente defendido contra o mundo exterior. Todo o espaço disponível era funcionalmente usado para o plantio de alimentos ou ervas medicinais.

A Idade Média constituiu, de fato, um período histórico de transição, rico no reexame de antigas idéias, na adaptação de velhas técnicas a novas situações, uma era de busca de novos caminhos ${ }^{14}$ No final do período, com o afrouxar do conflito político, o desenvolvimento do comércio e a acumulação de riquezas, os jardins, ligados inicialmente a uma paisagem fechada e fortemente defendida, tornaram-se maiores e mais elaborados, desenhados para o prazer e não só para a utilidade.

Houve uma mudança filosófica, exigindo um novo sentido de unidade: o homem já não se satisfazia com a reunião de preciosos fragmentos da natureza num conjunto perfeito; havia uma nova idéia de espaço, onde tudo começava a ser unido pela luz ${ }^{15}$

Essa idade de paisagem mais emocional do que intelectual, influenciou o futuro de dois modos diferentes: a) como inspiração para o romantismo dos sécs. XVIII e XIX; b) como um estandarte estético da composição assimétrica, quando o artesanato, componente essencial desse período, associou-se à estética renascentista; esta combinação deu início àquilo que Kenneth Clark define como "civilização" ${ }^{16}$, inaugurando uma fase na percepção da paisagem marcada por um novo sentido de espaço.

Existem duas razões que explicam esse momento: a primeira, de ordem sociológica, que reconhecia a necessidade de usufruir do caráter real do lugar onde se desenrolava a vida das pessoas e pelo qual tão recentemente se havia lutado para conservar; a segunda, de ordem filosófica, expressava a consciência de que o homem era livre para questionar o funcionamento da natureza ${ }^{17}$ 
Esse período, que teve início na Itália, refletia sinceramente o espírito do seu tempo: a paisagem era uma composição simples, harmoniosa e unificada e seu conjunto demonstrava perfeitamente o entendimento dos fatos físicos e intelectuais que entravam na sua composição, numa inspirada combinação de conceito e lugar.

A teoria propunha que o jardim fosse fortemente ligado à casa e à piaisagem circundante por terraços, alpendres e outras extensões, recomendatlas para vencer as dificuldades dos terrenos e permitir a vista das colinas e dos pos. Além disso, os jardins eram concebidos como retiros que promoviam o encontro de intelectuais, estudantes e artistas, para trabalhar e debater sobre música, ciência, literatura e arquitetura ${ }^{18}$.

Enquanto a Igreja permanecia implacável na defesa da teologia existente, resistente às críticas do comportamento moral que levaram à Reforma e alheia às descobertas astronômicas, os jesuítas, cujo entendimento dos conflitos da mente humana era muito agudo, iniciaram um processo fundamental de ruptura com relação à teologia medieval ${ }^{19}$ A base dessa ruptura era a aceitação de mudanças nas relações do homem com o universo, garantindo uma maior influência humana sobre a forma de seu próprio destino.

Isto levou a uma nova concepção de espaço que influenciou todos os campos do conhecimento, especialmente o Paisagismo e o Planejamento das cida$\operatorname{des}^{20} \mathrm{O}$ novo entendimento da paisagem marcou o fim de uma era, eliminou o jardim ortodoxo e preparou o caminho para a harmonia da geometria organizada com as formas naturais, que viria a ser a base da revolução inglesa da paisagem, no séc. XVIII.

No séc. XVII, a França atingiu seu maior período de riqueza e poder e, como conseqüência, tornou-se o centro difusor do bom gosto na Europa. $O$ desenvolvimento da arte dos canteiros e de uma nova teoria de desenho da paisagem, que considerava o homem como o centro do universo, preparou o terreno para o celebrado trabalho de André Le Nôtre, em meados do séc. $\mathrm{XVII}^{21}$

O norte da França, onde o período teve início, é relativamente plano e florestado e os jardins, portanto, tendiam a aparecer como clareiras na floresta. A topografia devia ser tratada com sutileza para possibilitar a diferenciação de níveis que permitisse a visão do conjunto da paisagem. Além disso, era difícil conseguir unidade entre os novos jardins e as construções existentes, protegidas por fossos e fortificações. Tornou-se óbvio que, apenas cons- 
truindo simultaneamente novos edifícios e jardins, poder-se-ia obter o efeito de unidade entre os espaços edificados e os não edificados.

O eixo central fortemente definido, a simetria absoluta, as proporções matemáticas e a perspectiva infinita da paisagem francesa do séc. XVII, refletiam tanto a riqueza, o poder e a estrutura social rígida da França, quanto o conceito emergente da ascendência do homem sobre a natureza e, principalmente, dos direitos divinos do Homem sobre os homens.

A paisagem barroca era visualmente limitada pela floresta circundante e os jardins eram desenhados para serem usados por muitas pessoas ao mesmo tempo; eram o centro do poder, com todas as funções políticas, diplomáticas e de entretenimento que isso implicava.

A paisagem tornou-se fantástica, teatral, concebida para o desenvolvimento de um drama, onde as pessoas eram os atores e não mais os filósofos.

\section{A PAISAGEM IDEAL: ALGUNS MARCOS FUNDAMENTAIS DO SÉC. XVIII}

Por volta de 1700, a Igreja tinha perdido o apoio das classes influentes e educadas, que passaram a defender a idéia de que o deus que devia ser cultuado era a Nação e não o Deus do Testamento.

Essas idéias eram apoiadas por um sonho de "paraíso terrestre", onde a harmonia entre o homem e a natureza, numa simplicidade primitiva, levaria a uma vida terrena espiritual e materialmente gratificante, dentro dos limites da nação. A discussão dessas idéias filosóficas, os estímulos das grandes viagens, a moda de colecionar trabalhos de pintores italianos do séc. XVII, tudo contribuiu para o surgimento de novas idéias estéticas.

Dentro dessa revolta contra a ordem estabelecida, foi de especial significado para a paisagem que, para ajudar a preencher o vácuo espiritual que perturbava os pensadores do séc. XVIII, Leibnitz e Voltaire passaram a se interessar pelos conhecimentos recentemente adquiridos na China. Os escritos de Confúcio foram traduzidos e estudados, promovendo uma atitude diante da vida, muito mais moral do que teológica ${ }^{22}$. Em oposição a isto, mas sempre a favor da revolta contra a ordem, colocava-se Rousseau, que defendia o retorno à natureza ${ }^{23}$

Entretanto, sob toda a dialética e toda a semântica que caracterizaram os pensadores do séc. XVIII, podia-se encontrar idéias que eram mais realísticas do que quaisquer outras dos períodos precedentes, porque eram asserções não somente sobre filosofia da estética, mas sobre a paisagem real, visível. 
Foi William Gilpin quem, entre 1768 e 1776, pela primeira vez, apresentou avaliações descritivas de lugares reais, relacionando seus atributos físicos com a resposta emocional que eles despertavam.

É nesse momento que se encontra, pela primeira vez, uma explosão de entusiasmo, resultante da efetiva união de duas correntes até então paralelas: o pensamento filosófico e a experiência prática da paisagem ${ }^{24}$

A possibilidade de identificar fontes de beleza na natureza, trouxe também a possibilidade de selecionar apenas o mais belo, eliminando o resto e construindo paisagens mais bonitas. Os líderes desse movimento voltaram-se entusiasticamente para os pintores, com a finalidade de descobrir uma escala de valores que permitisse, dentro do ambiente real, ligar os conceitos abstratos de beleza ao arranjo das árvores, gramados, pedras e água.

O novo desenho da paisagem foi influenciado pela união de três escolas opostas de pensamento: 1) o Classicismo Ocidental, originado do barroco italiano e da grande monarquia francesa, que toda a Europa copiou e disputou; 2) a Escola Inglesa, em revolta contra o classicismo da paisagem (embora não da arquitetura) e a favor de uma expressão paisagística totalmente nova e liberal; 3) a Escola Chinesa, cujos princípios de irregularidade (mas não de simbolismo) a tal ponto se confundiram com os da Escola Inglesa que ficaram conhecidos no continente europeu como princípios anglo-chineses ${ }^{25}$

Os três principais paisagistas ingleses do séc. XVIII foram Willian Kent (1684/1748), Lancelot Brown (1715/1783) e Humphry Repton (1752/1818).

Quando Kent começou a trabalhar profissionalmente, encontrou a moda paisagística inteiramente dominada por André Le Nôtre, lider do gosto paisagístico na Europa. Os padrões geométricos e regulares dominavam os grandes parques, como também os jardins menores. A água, usada para fins ornamentais, era confinada por margens circulares ou retangulares. Avenidas ligavam um ponto focal a outro. As vistas eram cuidadosamente selecionadas para transmitir a impressão de regularidade.

Tudo isso foi modificado por Kent, substituído por uma abordagem mais flexível e fluente. A forma dos caminhos, avenidas e corpos de água tornou-se curvilínea e irregular. Os agrupamentos de árvores e os espaços abertos, até então empregados para anular as linhas naturais da paisagem, passaram a ser desenhados para enfatizá-las.

Ao mesmo tempo, a demanda de matéria-prima, como conseqüência da Revolução Industrial, começou a dizimar as grandes florestas dos séculos 
anteriores, reduzindo, assim, o número de animais cuja caça tinha determinado a criação de parques reais (assírios, persas e mesmo franceses). Animais menores, particularmente a raposa, tornaram-se o principal alvo dos caçadores, o que requeria campos mais abertos para a prática desse tipo de esporte $^{26}$

Fortemente influenciado por Kent, com quem trabalhou, Brown surgiu como um dos mais influentes aperfeiçoadores do jardim inglês. Para ele, uma das funções principais dos jardins era guiar os visitantes no desfrutar das belezas naturais. Sua atenção e influência, embora tenha consolidado a posição de Kent, foi também responsável pela destruição de históricos jardins renascentistas na Inglaterra.

Repton, sucessor de Brown, foi um inovador especialmente sensível às então emergentes idéias da Escola Pitoresca. Seu trabalho era, quase todo, baseado na "associação", palavra encontrada nos escritos da maioria dos filósofos do séc. XVIII. Em 1790, Archibald Alison publicou "Essays on the nature and principles of taste", onde destaca como pontos principais da teoria da associação: a) o prazer estético não provém das qualidades intrínsecas dos objetos percebidos, mas das seqüências de idéias que, por associação, eles sugerem; b) tais seqüências de idéias, devem estar conectadas por algum tipo de encadeamento, devem ser capazes de produzir emoções e não podem ser submetidas a análises racionais; c) as qualidades estéticas dos objetos percebidos devem ser considerados como sinais ou expressões que, de acordo com a constituição da natureza individual, podem produzir emoções ${ }^{27}$

Esses princípios da teoria da associação, combinados aos padrões estéticos que predominariam no séc. XIX, marcaram o início da visão moderna da paisagem $^{28}$

\section{A PAISAGEM ROMÂNTICA DO SÉC. XIX: O BELO, O SUBLIME E O PITORESCO}

Ao final do séc. XVIII, a idéia de reconhecer a beleza não apenas na ordem de uma paisagem "domesticada", mas também nas paisagens "selvagens", estava em total sintonia com o início do movimento do Romantismo.

A recolocação dos papéis relativos desempenhados pela razão e pela imaginação, a preocupação com a liberdade, a ênfase no trabalho como forma de superar os obstáculos, que impediam a realização dos ideais humanos, encontraram expressão no envolvimento do homem com os processos naturais e tornaram-se fundamentais para o desenvolvimento da criatividade que marcou o séc. XIX. 
Anthony Ashley Cooper, Conde de Shaftesbury, filósofo liberal, influenciou decisivamente o pensamento estético do séc. XIX, ao lançar mão do sublime, até então um termo apenas literário, como explicação para as emoções despertadas pela paisagem. Shaftesbury afirmava que "na tentativa de abraçar o infinito, nós experimentamos o sublime. $O$ sublime é a experiência que temos ao contemplar fenômenos naturais muito grandes para serem compreendidos pelos sentidos ou pela imaginação" ${ }^{29}$

O que dominava a época era um excessivo desejo de escapar, através do romance, ao racionalismo opressivo que caracterizou o séc. XVIII ${ }^{30}$ As atitudes da socieade com relação à natureza, tendiam a se afastar do formalismo para o extremo oposto, o romantismo.

O coração do movimento romântico europeu estava na Alemanha. As escuras florestas nativas, as montanhas e os vales dos rios de um país que nunca esteve sob a ocupação romana, foram o cenário perfeito para o desenvolvimento do romantismo como uma filosofia "natural". Entretanto, o romantismo alemão estava muito mais voltado para a música, a literatura e a filosofia do que para a paisagem ${ }^{31}$ : Goethe explorou, mais ampla e profundamente do que ninguém, a mente humana e sua relação com o ambiente, respondendo igualmente ao classicismo e ao romantismo; Richard Wagner expressou musicalmente o sonho romântico alemão; a paisagem alemã, no entanto, era, ainda, um resultado de desunião política e econômica que caracterizava o país.

Na Inglaterra, o romantismo surgiu como reação a um ambiente insuportavelmente comprometido com a febre da Revolução Industrial. Com a expansão ferroviária cortando o território, com crescimento incontrolável das cidades e dos subúrbios, com os interesses nacionais voltados à obtenção de matéria-prima, o início do séc. XIX viu a Inglaterra num lamentável estado de decomposição ambiental, recorrendo ao romantismo, através da visão pitoresca, como um meio de resgatar a paisagem idilica representada pelos pintores do séc. XVII.

Mesmo que exista muita controvérsia sobre quando a visão pitoresca da paisagem apareceu pela primeira vez, o ano 1794 é um marco da sua aplicação ao paisagismo, com a publicação do "Essay on the picturesque", de Uvedale Price $^{32}$. No mesmo ano, Richard Payne Knight escreveu um poema intitulado "The landscape", onde exprime em versos os mesmos princípios que Price exprimiu em prosa. 
Price, Knight e Gilpin (que trabalhou no assunto quase trinta anos antes), diferiam consideravelmente nos detalhes de suas interpretações sobre o pitoresco. Entretanto, eles tinham alguns pontos em comum: a) todos concordavam em que as emoções despertadas pela paisagem não se encerravam nas considerações sobre o belo e o sublime, mas havia uma terceira categoria, o pitoresco, que evocava as qualidades da pintura paisagistica do séc. XVII; b) todos tinham em comum a crítica a um estilo de paisagismo que consideravam insípido, monótono, destituído de qualquer excitação, caracterizado por alguns poucos artifícios estereotipados.

Essa comunhão de interesses foi suficiente para permitir o início da Escola do Pitoresco ${ }^{33}$, onde se defendia que as qualidades que deveriam ser vistas numa paisagem eram a textura, a rugosidade, a assimetria, a irregularidade, $o$ segredo, o inesperado e, sobretudo, a impressão de uma situação natural ao invés de planos artificialmente construídos.

Em constraste com o belo, que requeria variações realizadas gradualmente, ou não dramaticamente e com o sublime que exigia o despertar de emoções fantásticas, as qualidades exaltadas pelos defensores do pitoresco eram a mudança súbita e um grau de variação suficientemente amplo para abranger extremos, incorporando aspectos por um lado belos e por outro sublimes.

Na América, o Romantismo encontrava sua maior expressão em Andrew Downing, cujas teorias paisagísticas incorporavam ao trabalho de Repton os princípios do pitoresco.

Downing popularizou o Romantismo na América criando paisagens à maneira inglesa, mas tendo o cuidado de enfatizar as qualidades características do ambiente local.

Enquanto a Escola Européia do Pitoresco pôde adotar, quase sem restrições, a Teoria da Associação, proposta por Alison em 1790, na América, essa doutrina mostrou-se inaceitável em sua essência, porque sugeria como ideal as associações com ruínas e relíquias, mitos e lendas, uma condição que dificilmente poderia ser atingida na paisagem "selvagem" do continente.

O pensamento paisagístico contemporâneo desse período era basicamente o pensamento inglês e Downing tornou-se, inevitavelmente, o seguidor dos princípios de Lancelot Brown. Entretanto, enquanto Brown acreditava que o mais importante era a paisagem natural e informal, Downing concedia um papel igualmente importante à "paisagem arquitetônica". 
A adoção de uma associação entre aspectos informais e aspectos arquitetônicos num estilo de paisagem que reconhecia as restrições e as potencialidades de cada lugar, lançou as raízes de uma nova filosofia paisagística fortemente defendida por Frederick Olmsted. O desenvolvimento dessa filosofia culminou com o entendimento definitivo de cidade e campo como um conjunto único, numa seqüência fluente de espaços edificados e não edificados.

O plano do Central Park e sua posterior implantação trouxe tanto a consciência da importância de preservar um dos mais preciosos recursos do período industrial, as áreas não urbanizadas das cidades, como o iniciou o movimento por um sistema nacional de Parques.

Além do despertar da consciência ambiental, estimulado pelo Movimento Romântico, um processo que começou, mas não se completou, no séc. XVIII, a grande contribuição do séc. XIX foi uma profusão de idéias que tornaram possível a compreensão da paisagem como uma criação de extrema importância no desenrolar da vida das pessoas.

\section{SÉC. XX: A EXPERIÊNCIA DA PAISAGEM}

Antes do término do séc. XIX, novas forças estavam produzindo mudanças fundamentais em praticamente todos os níveis e todas as regiões do mundo habitado.

É nos anos imediatamente anteriores e posteriores a 1890, que a maioria dos acontecimentos que distinguem o período contemporâneo do período moderno, começam a ficar visíveis pela primeira vez.

Parece fora de dúvida que não é possível estabelecer essa ou qualquer outra data como linha divisória entre os dois períodos, mas mesmo assim, é nesse momento que começam a se delinear os contornos de uma nova época ${ }^{34}$ Quando procuramos identificar as forças que puseram em movimento as novas tendências, os fatores que sobressaem são, de um lado, a Revolução Industrial e a sociedade européia do séc. XIX e, de outro lado, o "novo imperialismo", conseqüência das mudanças do modo de produção.

O fato central, marcando a ruptura entre os dois períodos, foi o colapso da tradição humanista que dominou o pensamento europeu desde o Renascimento. O motivo principal estava na desilusão provocada pelo descompasso entre os fundamentos filosóficos do humanismo, principalmente o respeito pela dignidade e pelo valor do indivíduo, e os resultados práticos observados, principalmente a despersonalização e a desumanização da classe trabalha- 
dora. Além disso, ocorreram mudanças básicas de estrutura, que deram forma ao mundo moderno 35

No início do século, o centro difusor da cultura ainda era a Europa, e o que chegava aos outros continentes eram modismos, subprodutos das tendências que surgiam a partir do contexto político, econômico e social europeu e, portanto, só ali poderiam se justificar.

Entre 1893 e 1920, a paisagem da América foi inteiramente dominada pelo classicismo europeu. As maiores cidades da América do Sul, como Rio de Janeiro, São Paulo e Buenos Aires, exibem, ainda hoje, importantes obras de arquitetura que, à época de sua concepção, compunham uma paisagem clássica ditada pela Escola de Belas Artes de Paris, árbitro do período para tudo o que era considerado esteticamente belo.

A mesma observação se aplica ao "City Beautiful Movement", nos Estados Unidos, cuja ordem rigorosamente clássica fazia contraste violento com o esquema romântico de Downing.

Entretanto, entre 1918 e 1945, o aparecimento dos Estados Unidos e da União Soviética como superpotências, a conseqüente alteração de posição da Europa, o colapso e transformação dos antigos imperialismos (britânico, francês e holandês), o ressurgimento da Ásia e da África no cenário político internacional, o reajustamento das relações entre os povos, caracterizou um período de transição, de tendências confusas e incertas. $O$ aspecto mais significativo desse período é o seu caráter mundial, conseqüência da industrialização, da vida urbana, da produção de massa, das novas formas de comunicação, da civilização tecnológica.

O paisagismo entrou no séc. XX marcado por um legado teórico que era de espírito essencialmente agrário. Essa abordagem se adaptava muito mal às novas paisagens de subúrbio da cidade industrial. Na América, entretanto, a disciplina já estava suficientemente desenvolvida para permitir o surgimento de várias frentes de avanço, a maioria das quais de fundo pseudo-romântico que, apesar disso, serviram de inspiração à luta de identificar e humanizar a paisagem do mundo da produção de massa ${ }^{36}$

Em 1929, o educador americano John Dewey publicou o livro "Experiência e Natureza", que, de certo modo, foi a semente do pensamento paisagístico do séc. XX. O "Naturalismo Americano", como ficou conhecido o movimento iniciado por Dewey, tinha como mensagem principal a de que a beleza não está nem nos objetos em si, nem nos olhos do observador, mas deve ser descoberta na relação entre o indivíduo e o ambiente, no que, em resumo, De 
wey chamou de "experiência de paisagem". A partir daí, propôs três importantes corolários: 1) desde que a experiência é um contato recíproco entre o indivíduo e o que ele experimenta, a distinção entre percepção e expressão é uma distinção sem significado, porque ambas são componentes de uma única relação, isto é, o indivíduo pode expressar ou não sua experiência, mas a percepção sempre existe; 2) desde que há umà variedade infinita de condições ambientais, existe também a possibilidade da experiência estética tomar inumeráveis formas; 3) toda experiência se dá através de mecanismos biológicos $^{37}$

Naturalmente, Dewey não estendeu suas teorias aos diversos campos do conhecimento mais do que o necessário para estabelecer sua validade geral. Entretanto, sua filosofia era o mais promissor ponto de partida para as pesquisas na estética do paisagismo. Isso fez com que se tornasse imprescindível trabalhar em detalhe, a conexão entre a experiência e a paisagem, sendo o primeiro passo, necessariamente, a aplicação dos princípios gerais da filosofia estética proposta às situações ambientais reais.

Na Europa, Christopher Tunnard concebeu a teoria funcionalista como resposta ao absolutismo do "Art Nouveau", que dominava a estética. Essa teoria tinha três linhas principais: 1) a abordagem funcional, segundo a qual os valores estéticos residem na economia dos meios de expressão e no descartar das "velhas roupas do passado", que são os estilos; 2) a abordagem empática, segundo a qual a natureza não deve ser olhada como um refúgio da vida, mas como um estímulo para o corpo e para a mente, não podendo, portanto, ser copiada, sentimentalizada ou dominada; 3 ) a abordagem artística, segundo a qual a busca sem proveito da beleza decorativa é uma atitude de qualidade discutível e, portanto, deve ser secundária no processo de criação ${ }^{38}$

Foi após a Segunda Guerra Mundial que as propostas de Dewey e Tunnard encontraram condições favoráveis à sua aplicação. América e Europa estavam empenhadas em construir e reconstruir suas paisagens dentro dos princípios propostos pelo naturalismo e pelo funcionalismo, o que originou uma diversidade de frentes de avanço, tão variadas quanto as possíveis interpretações dessas teorias.

Entretanto, todos os procedimentos envolviam, pela primeira vez, uma consciência geral do ambiente e de seus problemas de proteção, associada a medidas específicas que indicavam, finalmente, o cruzamento de fronteiras interdisciplinares. 
Segundo Barraclough ${ }^{39}$, pode-se razoavelmente afirmar que, ao final de 1960 , o longo período de transição entre a idade moderna e a idade contemporânea estava concluído e o "novo mundo" entrou em órbita. Nesse "novo mundo", as questões predominantes, das quais não se pode fugir, são os problemas da pobreza, do atraso e do excesso de população. Além disso, o progresso da sociologia ensinou que o grupo, e não o indivíduo, constitui a unidade básica da sociedade. Essas características do "novo mundo" influenciaram, de forma marcante, os estudos e propostas no campo do Paisagismo.

À medida que o aumento da população, da velocidade dos meios de transporte, da eficiência das comunicações, tornaram a vida mais complexa, também emergiu a consciência de que a paisagem tinha o papel de promover o encontro entre os grupos sociais, de modo que as atividades humanas se integrassem perfeitamente a um dado conjunto de circunstâncias físicas. Os valores, os hábitos e os objetivos dos usuários passaram a ditar as normas da paisagem.

Em 1955, Thomas Church publicou "Gardens are for People", onde explica, nas páginas introdutórias, a revolta do paisagismo contra as influências "imitativas", principalmente o ecletismo vitoriano ${ }^{40}$ Seus projetos exibiam o funcionalismo tão eficientemente ensinado pela Bauhaus (1919-1928), associado a uma influência oriental, especialmente japonesa, em termos de formas, balanço de forças, contrastes, equilíbrio, etc. É natural que esse processo, logo conhecido como estilo californiano, tenha se originado na Costa Oeste dos Estados Unidos, região com extensas relações comerciais com o Oriente ${ }^{41}$

É do início da década de 60 o livro "Landscape Architecture", de John O. Simonds, que procura considerar as "forças naturais" (sol, vento, temperatura, etc.) como elementos que, associados à circulação, promovem a organização dos espaços. A beleza é o resultado desse processo de relações harmoniosas $^{42}$

É também do mesmo período, o surgimento da percepção ambiental, um tipo particular de teoria interdisciplinar, com fortes ligações com a Psicologia. $\mathbf{O}$ conceito básico que apóia esses estudos é o de que o comportamento social é influenciado pelas atitudes com relação ao meio ambiente, tal como ele é percebido. $O$ fundamental é a imagem que o homem tem da paisagem e essa imagem pode ser interpretada de muitas formas diferentes.

Os aspectos psicológicos do movimento das pessoas na paisagem foram estudados e discutidos de formas diferentes, por Kevin Lynch, Gordon Cullen e Lawrence Halprin. 
Lynch, em 1959, publicou "The Image of the City", com estudos sobre a maneira pela qual o morador urbano visualiza seu ambiente. Para os residentes em um determinado lugar, os marcos, caminhos e limites dos trajetos cotidianos têm uma importância muito maior do que as características globais da paisagem desses lugares que eles, na maioria das vezes, não percebem ${ }^{43}$

No mesmo ano, Gordon Cullen, no livro "Townscape", afirma que, ao se deslocar pela cidade, as pessoas reagem não às construções isoladamente, mas à composição do grupo de construções, em sintese, à paisagem resultante do agrupamento das várias funções urbanas. Essa reação origina-se na sucessão de surpresas ou revelações súbitas de um determinado trajeto, que ele chamou de "visão serial"44

Para Lawrence Halprin, em contraste com o "City Beautiful Movement" ou com os princípios defendidos pela Escola de Belas Artes de Paris, no começo do século, o desenho da paisagem atual deve criar espaços para integrar as pessoas e não apenas os edifícios e, portanto, as pessoas são parte fundamental do processo de criar uma paisagem ${ }^{45}$

A forma da paisagem, em determinado momento, possui qualidades que resultam da organização de elementos controlados e de elementos não controlados ou indeterminados. Nessa última categoria se inclui a criatividade das pessoas no uso dos espaços públicos e particulares, que é o que confere, em última instância, a dinâmica social à paisagem.

Mas foi, sem dúvida, o "método ecológico" de McHarg que surgiu como a influência mais persuasiva no desenho da paisagem, nos últimos 20 anos. Entretanto, o termo "ecológico" é normalmente associado a conotações pré-humanas e pode ser de validade duvidosa num ambiente urbano antropocêntrico. Além disso, o Movimento Ambiental, que serviu de inspiração à proposta de McHarg, questiona as relaçoes homem-ambiente sob a forma de crítica sócioeconômica do modelo de crescimento dependente, ao qual o movimento atribui os abusos ambientais praticados na atualidade.

A proposta de McHarg, ao privilegiar o aspecto "natural" da paisagem ${ }^{46}$, coloca em plano secundário as complexas relações existentes entre os parâmetros sociais e a paisagem construída. A coerência entre o projeto de paisagismo e sua base ecológica, parece apoiar-se mais no contexto visual do que nas considerações econômicas. Se é amplamente aceito que os problemas de atraso, pobreza e superpopulação são manifestações de desequilíbrio da atuação de forças sócioeconômicas, então, uma proposta paisagística visual, sem a 
procura de uma estratégia social de longo prazo, será sempre uma mera decoração, por mais marcante que possa ser.

Na dinâmica que caracteriza a evolução da paisagem, o fator mais constante tem sido, sem dúvida, o mecanismo humano de percepção pelos cinco sentidos, através dos quais todos os estímulos passam para despertar nossas emoções. Embora esse mecanismo seja bastante estável, a expressão das emoções despertadas pela paisagem, seja através da ciência, da pintura, da literatura ou do paisagismo, varia a cada período histórico.

$\mathrm{Na}$ literatura, a paisagem, ao ser codificada em palavras pelo escritor e decodificada em paisagem pelo leitor, apresenta duas oportunidades de enriquecimento pela imaginação: as paisagens podem ser descritas e compreendidas em termos exagerados, mas que se admite como pertencentes ao simbolismo do mundo real ou do mundo dos sonhos ${ }^{47}$

Na pintura, a representação da paisagem vai das coisas às impressões, dos símbolos às interpretações. $\mathrm{O}$ pintor ou o observador podem tomar algumas liberdades de interpretação para representar ou entender uma paisagem tal como desejam que ela seja vista. Entretanto, a expressão de tudo isso só pode ser feita a partir de um único ponto de vista espacial ${ }^{48}$

A intervenção da ciência na paisagem alterou radicalmente o conceito de natureza. A palavra natureza, entre seus vários significados, pode indicar a parte do universo não criada pelo homem, apreendida pelos sentidos. Mas, desde que o telescópio e o microscópio aumentaram imensamente a visão desse conjunto, a natureza que se pode ver com os sentidos, ampliou-se muito acima da imaginação.

Esse fato, sem dúvida, deixou suas marcas na paisagem moderna: "a natureza, não só nos parece simultaneamente maior e menor, como também parece igualmente ter perdido sua unidade... Nos últimos anos, perdeu-se, inclusive, a fé na estabilidade daquilo que chamamos ordem natural ${ }^{49}$

O processo de emancipação do homem com relação ao ambiente, embora envolva, lamentavelmente, o empobrecimento e até mesmo a destruição do simbolismo natural da cultura humana, não é um processo indesejável. $\mathrm{Na}$ verdade, o conceito normal de abrigo para o homem moderno tem a forma de edifícios e, desde que o homem é de natureza gregária, a aglomeração de edifícios em diferentes formas urbanas não está em desacordo com o seu comportamento. 
A perda progressiva das raízes históricas e regionais das diferentes culturas, a adoção generalizada dos modismos estéticos, é que permitiram a emergência de paisagens genuinamente "internacionais" na sua gama de elementos de composição. A crença de que a cidade é uma entidade separada da natureza, e mesmo oposta a ela, dominou a forma pela qual a cidade é percebida e continua a afetar a forma como ela é construída. As cidades parecem forjadas amplamente pelas forças sociais e econômicas, com a natureza desempenhando o pequeno papel de embelezar seus espaços com árvores e parques.

Há um contraste violento, senão mesmo um conflito entre a diversidade de frentes de estudo da paisagem, surgidas no séc. XX, e a homogeneidade de soluções paisagísticas decorrentes do isolamento da cidade em relação à natureza.

Atualmente, os estudos de paisagismo se apóiam na consciência de que a paisagem contemporânea tem o papel de promover o encontro entre os grupos sociais e isto pode se dar de muitas maneiras diferentes. Nossa vida se desenvolve cada vez mais nos espaços públicos, que devem abrigar tanto os propósitos humanos, quanto os processos naturais.

O enriquecimento da vida cotidiana se dá através da possibilidade de deslocamento pelos dos espaços da paisagem e entre seus edifícios. Isto permite múltiplas visões do ambiente e a descoberta de emoções e encantos sempre renovados.

Da mesma forma que a arte, que de acordo com Paul Klee "não reproduz o que se pode ver, mas torna as coisas visíveis", o paisagismo tem a responsabilidade de tornar visíveis as necessidades sociais no uso dos espaços não edificados. Essa responsabilidade é definida em termos do papel potencial que o paisagismo representa dentro de um determinado contexto social e ambiental. Cabe, portanto, ao paisagismo deste final de século, o papel de tornar visível o valor social da natureza em sua integração perfeita com as cidades, os subúrbios e os campos.

\section{BIBLIOGRAFIA}

APPLETON, Jay. The Experience of Landscape. London, John Wiley and Sons, 1975.

BARRACLOUGH, Geoffrey. Introdução à História Contemporânea. Rio de Janeiro, Zahar, 1976.

BRONOWSKY, J. A Escalada do Homem. São Paulo, Martins Fontes/UnB, 1983.

CERASI, Maurice. La Lectura del Ambiente. Buenos Aires, Infinito, 1977. 
CHURCH, Thomas Delano. Gardens are for People. New York, McGraw Hill, 1987.

CLARK, Kenneth. Paisagem na Arte. Lisboa, Ulissea, 1961.

. Civilizaçāo. São Paulo, Martins Fontes/UnB, 1980.

CLIFFORD, Derek. A History of Garden Design. London, Farber and Farber, 1962.

CULLEN, Gordon. Paisagem Urbana. São Paulo, Martins Fontes, 1983.

ECKBO, Garret. Landscape for Living. New York, F.W. Dodge Corp., 1950.

. The Landscape we See. New York, McGraw Hill, 1969.

FERRARA, Guido. L'Architettura del Paesaggio Italiano. Padova. Marsilio, 1968.

HALPRIN, Lawrence. The RSVP Cycles: Creative Process in Human Environment. New York, George Braziller Inc., 1973.

JACOBS, Peter. Sustaining landscapes: sustaining societies. Amsterdam, Landscape and Urban Planning, n. 13, 1986, p. 349-358.

JELLICOE, Geoffrey and Suzan. The Landscape of Man: Shapping the Environment from Prehistory to the Present Day. New York, Van Nostrand Reinhold Co. Inc., 1982.

LAURIE, Michael. An Introduction to Landscape Architecture. London, Pitman Publ. Ltd. 1978.

LYNCH, Kevin. Managing the Sense of a Region. Cambridge, Murray Printing Co., 1981.

. De que Tiempo es este Lugar? Barcelona, Gustavo Gilli, 1975.

. Planificación del sitio. Barcelona, Gustavo Gilli, 1980.

. Imagem da Cidade. São Paulo, Martins Fontes, 1980.

McHARG, Ian. Design with Nature. New York. The Natural History Press, 1969.

RADMALL, Peter. Landscape by Default. London, Landscape Design, Feb., 1986, p. 17-19.

SEDDON, George. Landscape planning: a conceptual perspective. Amsterdam, Landscape and Urban Planning, n. 13, p. 335-347, 1986.

SIMONDS, John Ormsbee. Landscape Architecture. New York, McGraw Hill, 1961.

SPIROS, Anne Whiston. The Granite Garden: Urban Nature and Human Design. New York, Basic Books, 1984.

TOBEY, JR.; George B. A History of Landscape Architecture: the Relationship of People to Environment. New York, Elsevir Publ., 1973. 


\section{NOTAS}

(1) Appleton, J., 1975, p. 21.

(2) Appleton, J. 1975, p. 1.

(3) Jellicoe, G., 1982, p. 7.

(4) Cerasi, M., 1977, p. 174.

(5) Appleton, J. 1975, p. 2.

(6) Jellicoe, G., 1982, p. 23.

(7) Jellicoe, G., 1982, p. 49.

(8) Tobey Jr., G., 1973, p. X.

(9) "Há muitas maravilhas, mas nenhuma é tão maravilhosa quanto o homem. Ele atravessa, ousado, o mar grisalho arrebatado pelo vento sul tempestuoso, indiferente às vagas enormes, na iminência de abismá-lo: e exaure a terra eterna, infatigável deusa suprema, abrindo-a com arado em sua ida e volta, ano após ano, auxiliado pela espécie eqüina ... Soube aprender sozinho ... a proteger-se das nevascas gélidas, duras de suportar a céu aberto, e das adversas chuvas fustigantes; ocorrem-lhe recursos para tudo... (Sófocles, Antigona, v. 285 e seguintes).

(10) "Era noite e na terra os corpos fatigados gozavam o plácido repouso; aquietaramse as florestas e o mar tempestuoso quando os astros percorreram metade do seu curso, quando o campo todo silencia; os rebanhos e as aves multicores e os animais que habitam os límpidos lagos e os que os campos bravios cobertos de sarças têm por moradia, na silenciosa noite adormecidos, protegidos pelas bençãos da natureza, aliviavam os seus cuidados com os corações esquecidos das fadigas." (Virgílio, Eneida, IV).

(11) Clark, K., 1961, p. 20.

(12) "Centenas de árvores copadas, de troncos curtos, amplos ramos, que haviam presenciado, talvez, a majestosa marcha dos soldados romanos, lançavam os braços bondosos sobre o espesso tapete do mais delicioso relvado... em outros, afastavam-se, formando amplas paisagens, em cujo emaranhado a vista se deliciava ao estender-se, enquanto a imaginação as considerava como caminhos que conduziam a cenários ainda mais belos, de rústica solidão." (Boccaccio, G.; Decameron, $10^{\mathrm{a}}$ jornada, $3^{\mathrm{a}}$ novela).

(13) Clark, K., 1961, p. 21.

(14) Tobey Jr. G., 1973, p. 75.

(15) Clark, K., 1961, p. 35.

(16) Clark, K. 1961, p. 40.

(17) Appleton, J., 1975, p. 50.

(18) Laurie, M., 1978, p. 22.

(19) Jellicoe, G. 1982, p. 154.

(20) Jellicoe, G., 1982, p. 164.

(21) Laurie, M., 1978, p. 25.

(22) Jellicoe, G. 1982, p. 205.

(23) Rousseau, J. J. The new Heloise.

(24) Appleton, J. 1975, p. 26.

(25) Jellicoe, G., 1982, p. 205.

(26) Tobey Jr. G., 1973, p. 128. 
(27) Appleton, J., 1975, p. 38.

(28) Appleton, J. 1975, p. 39.

(29) Appleton, J. 1975, p. 27.

(30) Clark, K. 1961, p.77.

(31) Jellicoe, G., 1982, p. 251.

(32) Appleton, J. 1975, p. 34.

(33) Appleton, J. 1975, p. 35.

(34) "Os anos decorridos entre 1890, quando Otto Bismarck se retirou da cena política, e 1961, quando John Kennedy tomou posse como presidente dos Estados Unidos, constituíram um amplo divisor de águas entre duas épocas: de um lado situa-se a idade contemporânea, ainda nos seus primórdios, do outro lado alarga-se o vasto panorama da idade moderna, com seus píncaros familiares; Renascimento, Iluminismo e Revolução Francesa.' (Barraclough, G. d1976, p. 12/13).

(35) Barraclough, G. 1976, p. 21.

(36) Jellicoed, G. 1982, p. 307.

(37) Appleton, J. 1975, p. 49/50.

(38) Tobey Jr., G., 1973, p. 200.

(39) Barraclough, G., 1976, p. 29.

(40) Church, Thomas D., 1983, p. 5/6.

(41) Tobey Jr. G., 1973, p. 203.

(42) Simonds, J. O. 1961, p. 229.

(43) Lynch, K., 1980.

(44) Cullen, G. 1983,, p. 99/111.

(45) Halprin, L. 1973, p. 190/195.

(46) McHarg, 1969, p. 7 a 19.

(47) Clark, K., 1961, p. 74/176.

(48) Appleton, J. 1975, p. 213.

(49) Appleton, J., 1975, p. 203. 